\title{
EFEITO DA IRRIGAÇÃO E UTILIZAÇÃO DE LIXO ORGÂNICO NA FORMAÇÃO DE MUDAS DE EUCALIPTO
}

\section{EFECT OF IRRIGATION AND USE OF ORGANIC URBAN RESIDUES ON GROWING EUCALYPTUS SEEDLINGS}

\section{Lui, J. J. ${ }^{1}$; Galbiatti, J. A. ${ }^{2}$; Melheiros, E. B. ${ }^{2}$}

\author{
${ }^{1,2}$ Faculdade de Ciências Agrárias e Veterinárias - FCAV/UNESP - Via de Acesso \\ Prof. Paulo Donato Castelani, s/n ${ }^{\circ}$, CEP: 14870-000, Jaboticabal, SP \\ e-mail: jadislaului@hotmail.com; gabi@fcav.unesp.br; euclides@,fcav.unesp.br
}

\section{RESUMO}

Mesmo quando não se encontram em áreas agrícolas, o descarte de resíduos orgânicos, quase sempre não ocorre dentro de especificações adequadas. Dentro desta ótica fica clara a necessidade de se buscarem parâmetros mais seguros para o uso desses resíduos, permitindo a sustentabilidade dos ecossistemas, com mínimas alterações. O uso imediato à coleta, do Resíduo Sólido Orgânico Urbano (R.S.O.U.), sem a prática da compostagem, submetendo-o a dessecagem, trituração e aplicação no solo, pode ser a solução para a eliminação da contaminação do lençol freático proporcionada pelo acúmulo desse material de forma concentrada e localizada, quer seja a céu aberto, ou na prática da compostagem. No Brasil e no Mundo, ainda não se produziu informações consistentes que possibilitem conhecimentos suficientes, para tomadas de decisões que estão sendo exigidas, em razão do crescente volume de resíduos produzidos e os impactos ao meio ambiente. Este trabalho objetivou estudar o efeito da irrigação associada ao uso de R.S.O.U. para formação de mudas de eucalipto. A pesquisa foi desenvolvida na Faculdade de Ciências Agrárias e Veterinárias - UNESP, Campus de Jaboticabal, SP. O delineamento estatístico adotado foi o esquema fatorial inteiramente casualizado. Foram utilizados onze substratos: dois tipos de solos (Latossolo Roxo e Latossolo Vermelho Escuro), com e sem adubação mineral, seis misturas de solo e R.S.O.U., e um utilizado somente R.S.O.U. Sementes de eucalipto var. Citriodora Hooker, foram semeadas diretamente em tubetes e irrigadas com base em dois métodos de quantificação da água (tanque classe "A" e determinação da massa), em quatro níveis $(50,75,100$ e $130 \%$ da evapotranspiração). Os dados coletados e analisados estatisticamente demonstraram 
que diferentes doses de R.S.O.U., não compostado previamente, misturadas aos solos destinados à produção de mudas de eucalipto, causam efeitos negativos na sobrevivência das plantas, sendo mais evidentes para doses acima de $20 \%$ e a irrigação conduzida com base no método de pesagem foi mais eficiente na manutenção das plantas.

Palavras-chave: Mudas de eucalipto.Resíduo orgânico.Substrato. Método de irrigação.

\section{ABSTRACT}

Even if not specifically for agricultural areas, the disposal of organic residues seldom occurs according to adequate specifications. In this context, the search for safer parameters for the use of these residues in order to allow the sustainability of ecosystems is increasingly important. The use of Urban Organic Solid Residue (UOSR) shortly after collection without the practice of composting techniques, submitted to desiccation, grinding and applied in soil, may be the solution to avoid contamination of the ground water caused by the concentrated and localized accumulation of this material either in the open or through the practice of composting techniques. Studies in Brazil and the world on the characteristics and possibilities of using Urban Solid Residue (USR), and more specifically UOSR, have not yet yielded information that would result in sufficient knowledge for making decisions, which are necessary to respond to immediate demands due to the increasing volume of residues produced. With the intention of contributing more information, the aim of this study was to examine the effects of irrigation associated with the use of UOSR on growing eucalyptus seedlings. This research was developed in the School of Agricultural and Veterinary Sciences - UNESP (Universidade Estadual de São Paulo) Campus of Jaboticabal. The statistical delineation used was fully random in a factorial design. Eleven substrata were formulated using two types of soil, a purple latossol and a dark red latossol, with and without chemical fertilization, six soil mixtures containing UOSR, and UOSR alone. In direct seeding in soil blocks, Citriodora Hooker eucalyptus seeds were used, using two water quantification methods to be applied through irrigation, class "A" tank methods and through weighing the substrata in four levels $(50 \%, 75 \%, 100 \%$ and $130 \%$ of evapotranspiration). The data collected were statistically analyzed and show that mixtures with $20 \%$ or more of UOSR presented harmful effects on plant development, being more evident in doses above $20 \%$, and irrigation based on the weighting method was more efficient in the production of eucalyptus seedlings through direct seeding.

Keywords: Seedling. Water.Organic residue. Substrata. Irrigation methods. 


\section{INTRODUÇÃO}

Os resíduos sólidos constituem hoje um dos principais problemas enfrentados pela humanidade. $\mathrm{O}$ acentuado crescimento demográfico seguido do grande desenvolvimento tecnológico vem aumentando consideravelmente a quantidade de resíduos sólidos refugados pelo homem, problemática que assume proporções ainda maiores, na medida em que se verifica a redução da disponibilidade de áreas para disposição dos rejeitos e seu alto potencial de contaminação do meio ambiente (VERAS, 2004).

Problemas ambientais seriam reduzidos caso fosse possível utilizar o Resíduo Sólido Orgânico Urbano (R.S.O.U.) na agricultura, ocorrendo economia e melhoria da qualidade de vida. As propriedades físicas e químicas do solo, como a agregação das partículas, a porosidade, a retenção de umidade, a condutividade hidráulica, a capacidade de campo e a fertilidade são favorecidas pelo uso de matéria orgânica. Estes fatores importantes para a melhoria das condições dos solos agricultáveis, podem tornar economicamente viáveis os solos pobres e de baixa sustentabilidade produtiva. (BRAUN, 1964, KIEHL, 1985, FERNANDEZ et al., 1987, ANDRIOLI et al., 1991; RUIZ e TEIXEIRA,1991).

A compostagem de resíduos orgânicos é um dos métodos mais antigos de reciclagem, durante o qual a matéria orgânica é transformada em fertilizante orgânico. Além de ser uma solução para os problemas dos resíduos sólidos, o processo de compostagem proporciona o retorno de matéria orgânica e nutrientes ao solo. Este processo é resultado da decomposição biológica aeróbia do substrato orgânico, sob condições que permitam o desenvolvimento natural de altas temperaturas, com formação de um produto suficientemente estável para armazenamento e aplicação ao solo, sem efeitos ambientais indesejáveis, segundo Haug, (1980); Mesquita e Pereira Neto, (1992), citados por Jahnel et al.,(1999), porém este processo é demorado levando até uma centena de dias para a estabilização.

O uso imediato à coleta, do Resíduo Sólido Orgânico Urbano (R.S.O.U.), sem a prática da compostagem, submetendo-o a dessecagem, trituração e aplicação no solo, pode ser a solução para a eliminação da contaminação do lençol freático causada pelo acúmulo desse material de forma concentrada e localizada, quer seja a céu aberto, ou na prática da compostagem. Portanto, seria interessante se o material orgânico fosse utilizado sem passar pela prévia compostagem ganhando-se tempo e espaço.

O êxito na formação de florestas de alta produção depende, em grande parte, da qualidade das mudas plantadas, que além de terem que resistir às condições adversas encontradas no campo após, o plantio deverão sobreviver e, por fim, produzir árvores com crescimento volumétrico economicamente desejável (GOMES et al., 1991).

A sobrevivência, o estabelecimento, a freqüência dos tratos culturais e o crescimento inicial das florestas são avaliações necessárias para o sucesso do 
empreendimento florestal, o que está diretamente relacionado com a qualidade das mudas por ocasião do plantio (GOMES et al., 1991; FONSECA, 2000), merecendo ressaltar que o potencial genético, as condições fitossanitárias e a conformação do sistema radicular são importantes para a boa produtividade dos povoamentos florestais (CARVALHO, 1992).

Com relação à produção de mudas de espécies vegetais, a quantidade das necessidades hídricas, em suas fases de formação e desenvolvimento, é de fundamental importância. Como reconhecido na literatura, a falta de água pode levar ao estresse hídrico e diminuir a absorção de nutrientes pelas plantas. Já o excesso pode favorecer a lixiviação dos nutrientes e ainda proporcionar microclima favorável ao desenvolvimento de doenças, além das questões sócio-ambientais relativas à economia de água e acúmulo de lixiviados no solo (LOPES, 2005).

Considerando os problemas advindos da geração de resíduos orgânicos urbanos, o presente trabalho teve por objetivo estudar o efeito da utilização de lixo orgânico sem compostagem e da irrigação no desenvolvimento de mudas de eucalipto.

\section{MATERIAL E MÉTODOS}

O experimento foi desenvolvido na Área Demonstrativa e Experimental de Irrigação do Departamento de Engenharia Rural da Faculdade de Ciências Agrárias e Veterinárias - UNESP, Jaboticabal, SP, localizada nas coordenadas 21ำ' $22^{\prime}$ " latitude sul e $48^{\circ} 18^{\prime} 58^{\prime \prime}$ longitude oeste, à altitude média de 575 metros (IBGE, 1971).

A classificação climática para a região, segundo classificação climática de Kooppen , é Cwa: subtropical com verão úmido e inverno relativamente seco. A temperatura média anual é de aproximadamente $22,2^{\circ} \mathrm{C}$, sendo que nos meses de junho e julho se aproxima de $12,6^{\circ} \mathrm{C}$ e, de dezembro a fevereiro, se aproxima de $30,1^{\circ} \mathrm{C}$. A umidade relativa do ar média é de $75 \%$, podendo atingir $15 \%$ nos meses mais secos. A precipitação pluviométrica média anual é $1430 \mathrm{~mm}$, sendo que $85 \%$ das chuvas ocorrem de outubro a março.

$\mathrm{O}$ delineamento experimental utilizado foi o inteiramente casualizado, num esquema fatorial $(2 \times 11 \times 4 \times 5)$ com 3 repetições. Os fatores consistiram de: 2 tipos de controle da irrigação (método do tanque classe A e método da pesagem), 11 substratos (Tabela 1), 4 níveis de irrigação $(50,75,100$ e 130\% da ET) e 5 estádios de crescimento $(15,29,41,53$ e 79 dias da semeadura). 
TABELA 1 - Composição dos substratos.

\begin{tabular}{cc}
\hline SUBSTRATOS & COMPOSIÇÃO \\
\hline S1 & Solo A em condição natural \\
S2 & Solo B em condição natural \\
S3 & Solo A com adubação mineral \\
S4 & Solo B com adubação mineral \\
S5 & Mistura de $80 \%$ de solo A e $20 \%$ de R.S.O.U. \\
S6 & Mistura de $80 \%$ de solo B e $20 \%$ de R.S.O.U. \\
S7 & Mistura de $60 \%$ de solo A e $40 \%$ de R.S.O.U. \\
S8 & Mistura de $60 \%$ de solo B e $40 \%$ de R.S.O.U. \\
S9 & Mistura de $20 \%$ de solo A e $80 \%$ de R.S.O.U. \\
S10 & Mistura de $20 \%$ de solo B e $80 \%$ de R.S.O.U. \\
S11 & R.S.O.U. puro \\
\hline
\end{tabular}

O solo A correspondeu a um Latossolo Roxo de classe textural argilosa e o solo B correspondeu a um Latossolo Vermelho Escuro de classe textural média, ambos obtidos na profundidade de 0 -1 metro.

O R.S.O.U. foi obtido a partir da coleta aleatória do resíduo sólido urbano (R.S.U.) em um bairro de classe média alta na cidade de Jaboticabal. As múltiplas coletas foram homogeneizadas e selecionadas, resultando nas frações inorgânica e orgânica. A fração orgânica (restos de alimentos, cascas de frutas, etc.) foi colocada em bandejas e levada à estufa com circulação de ar forçada, à temperatura de $70^{\circ} \mathrm{C}$, até adquirir massa constante. Após a secagem, o material foi triturado em triturador de grãos modelo DPM-4 e peneirado em peneira de furo redondo de diâmetro de 2 $\mathrm{mm}$. O material que passou pela peneira constituiu-se no R.S.O.U. A fração inorgânica (plástico, vidro, ferro, alumínio, cobre, etc.), foi descartada.

Os substratos foram submetidos a análises granulométrica e química, realizadas nos laboratórios do Departamento de Solos e Adubos da Faculdade de Ciências Agrárias e Veterinárias - UNESP, Jaboticabal. As análises granulométricas foram realizadas através do método da pipeta, utilizando-se $\mathrm{NaOH} 0,1 \mathrm{~mol} \mathrm{~L}^{-1}$ como dispersante, tempo de repouso 24 horas e agitação lenta, sendo as frações determinadas segundo Day (1965).

As análises químicas referentes às determinações de acidez trocável $\left(\mathrm{Al}^{3+}\right)$, de macronutrientes (cálcio, magnésio, potássio trocáveis e fósforo disponível) e de micronutrientes $(\mathrm{B}, \mathrm{Cu}, \mathrm{Fe}, \mathrm{Mn}$ e $\mathrm{Zn}$ ), foram realizadas utilizando-se os métodos descritos por Raij et al. (1987). O pH foi determinado potenciometricamente utilizando a relação solo: $\mathrm{CaCl}_{2}$ 0,01M. Para a determinação do carbono orgânico, seguiu-se a metodologia EMBRAPA (1979).

Os resultados da análise granulométrica dos solos e do R.S.O.U. encontram-se na Tabela 2 e os resultados das características químicas dos solos e do R.S.O.U. encontram-se na Tabela 3. 
TABELA 2 - Análise granulométrica dos solos e do R.S.O.U. empregados no experimento.

\begin{tabular}{ccccc}
\hline Classe & Argila & $\begin{array}{c}\text { Silte } \\
\mathrm{gkg}^{-1}\end{array}$ & Areia & Total \\
\hline Solo A & 530 & 230 & 340 & 1000 \\
Solo B & 250 & 70 & 680 & 1000 \\
R.S.O.U. & 130 & 410 & 460 & 1000 \\
\hline
\end{tabular}

R.S.O.U.: Resíduo Sólido Orgânico Urbano (relação C/N = 23/1)

TABELA 3 - Características químicas dos solos e do R.S.O.U. empregados no experimento.

\begin{tabular}{cccccccccccccc|c}
\hline Solo & PH & M.O. & P & $\mathrm{K}$ & $\mathrm{Ca}$ & $\mathrm{Mg}$ & $\mathrm{H}+\mathrm{Al}$ & $\mathrm{SB}$ & $\mathrm{T}$ & $\mathrm{B}$ & $\mathrm{Cu}$ & $\mathrm{Fe}$ & $\mathrm{Mn}$ & $\mathrm{Zn}$ \\
& & & & & & & & & & & & & & \\
& $\mathrm{CaCl}_{2}$ & $\mathrm{gdm}^{-3}$ & $\mathrm{mgdm}^{-3}$ & $<----------\mathrm{mmol} \mathrm{dm}^{-3}----------->$ & $<-------------\mathrm{mgdm}^{-3}-------------->>$ \\
\hline A & 6,0 & 21 & 43 & 1,5 & 34 & 30 & 20 & 65,5 & 85,5 & 0,13 & 1,4 & 6,0 & 7,4 & 0,6 \\
B & 4,4 & 15 & 15 & 1,6 & 12 & 5 & 38 & 18,6 & 56,6 & 0,13 & 0,4 & 14,0 & 5,5 & 0,3 \\
RSOU & 6,0 & 193 & 310 & 45,0 & 250 & 50 & 22 & 345,0 & 367,0 & 8,86 & 0,9 & 9,0 & 7,9 & 4,1 \\
\hline
\end{tabular}

R.S.O.U.: Resíduo Sólido Orgânico Urbano (relação C/N = 23/1)

$\mathrm{Na}$ semeadura, os tubetes foram preenchidos manualmente conforme os tratamentos. A irrigação foi efetuada inicialmente até atingir a capacidade de campo, quando foram semeadas 4 sementes por tubete, cobertas com uma camada de $2 \mathrm{~mm}$ de solo peneirado. O substrato foi coberto com sacos de aniagem, sendo retirados assim que as plântulas emergiram. O desbaste foi efetuado 15 dias após a semeadura, deixando uma muda por tubete.

Os tratamentos dos solos com adubação química (S3 e S4), consistiram da adubação foliar Nutri-Rápido (NPK + micronutrientes) na formulação 16-32-16, aplicando-se $25 \mathrm{ml} /$ tubete/vez, aos 35 e aos 42 dias após a semeadura, nas dosagens respectivas de $1 \%$ e $4 \%$ de adubo foliar, sendo esta última acrescida de salitre do Chile, uréia e $\mathrm{KCl}$. Todos os tratamentos receberam aos 56 dias uma rega de $0,05 \mathrm{~g}$ de Salitre do Chile e aos 63 dias uma rega com 1\% de uréia e 1\% de $\mathrm{KCl}$.

Após a semeadura os substratos foram colocados em capacidade de campo e, durante 30 dias, receberam duas irrigações diárias conforme rotina de um viveiro de mudas. Após este período, os substratos foram colocados novamente em capacidade de campo e iniciado a irrigação pelos dois métodos de controle: pelos métodos do Tanque Classe A (TCA) e da determinação das massas (PS), a níveis de 50, 75, 100 e $130 \%$ dos valores diários determinados.

A área do experimento foi mantida isenta de plantas daninhas através de capina manual nos tubetes e de capinas manuais nas imediações das bandejas suporte dos tubetes. Nenhum defensivo químico foi utilizado para o combate das plantas daninhas, pragas e doenças. 
Para a determinação do número de tubetes com plantas vivas, contagens foram efetuadas aos 15, 29, 41, 53 e 79 dias após a semeadura. Nestas mesmas datas, em 10 plantas por tratamento, foram determinadas: altura média, considerando-se à distância do colo da planta à extremidade da folha que atingiu a maior distância da base da planta e o número médio de folhas por planta.

As análises estatísticas foram realizadas pelo PROC GLM do SAS. As comparações de médias foram realizadas utilizando-se o teste de Tukey a 5\% de probabilidade.

\section{RESULTADOS E DISCUSSÃO}

Comparando o número médio de tubetes com plantas vivas em diferentes épocas após a semeadura (Tabela 4), verificou-se que aos 15 e 29 dias os substratos estudados não apresentaram diferenças significativas ( $p>0,05)$. Verificou-se que aos 41 dias somente o substrato $\mathrm{S} 11$ apresentou diferença significativa no número de plantas vivas. Aos 53 e 79 dias, somente os substratos S9, S10 e S11 diferiram estatisticamente dos demais. As diferenças, segundo Galbiatti (1992), podem estar associadas aos tipos de matéria orgânica ativa e inativa; a matéria orgânica ativa pode se decompor através do processo de fermentação e formar húmus, enquanto a matéria orgânica inativa ou humificada não está sujeita a decomposição intensa. A fração húmica age principalmente nas propriedades físicas e físico-químicas do solo, tornando-se fonte de nutrientes para as plantas. Além disso, o composto orgânico imaturo com relação $\mathrm{C} / \mathrm{N}$ alta, causa imobilização do nitrogênio, levando à deficiência deste elemento no solo.

A aplicação agronômica do composto de lixo urbano, quando obtido de modo adequado, é viável devido à sua riqueza em matéria orgânica e nutriente, à ausência de microrganismos patogênicos (XIN et al., 1992; MELO et al., 1997; CRAVO et al., 1998) e às melhorias das condições de cultivo do solo (aumento do teor de matéria orgânica, elevação do $\mathrm{pH}$, redução da acidez potencial e aumento da disponibilidade de fósforo, potássio, cálcio e magnésio), da nutrição e produção dos vegetais (KIEHL, 1985; CRAVO, 1995; LIMA et al., 1999; OLIVEIRA, 2000; ABREU JR. et al., 2000; MONTOVANI et al., 2005). 
TABELA 4 - Número médio de tubetes com plantas vivas, avaliados aos 15, 29, 41, 53 e 79 dias após a semeadura.

\begin{tabular}{ccccccc}
\hline substrato & \multicolumn{7}{c}{ Avaliações } \\
\cline { 2 - 7 } & 15 & 29 & 41 & 53 & 79 \\
\hline S1 & 23,04 a A & 23,50 a A & 22,00 a AB & 20,42 a A & 19,17 a A \\
S2 & 25,10 a A & 24,92 a A & 23,13 a AB & 22,21 a A & 21,54 a A \\
S3 & 22,38 a A & 22,25 a A & 20,42 a AB & 18,17 a AB & 17,25 a A \\
S4 & 26,46 a A & 26,13 a A & 25,42 a A & 23,50 a A & 22,54 a A \\
S5 & 25,21 a A & 26,08 a A & 24,92 a AB & 23,38 a A & 22,42 a A \\
S6 & 22,54 a A & 23,04 a A & 21,46 a AB & 19,96 a A & 18,71 a A \\
S7 & 23,67 a A & 23,96 a A & 22,63 a AB & 20,92 a A & 19,21 a A \\
S8 & 23,88 a A & 24,42 a A & 22,96 abAB & 19,88 abA & 17,92 bA \\
S9 & 25,71 a A & 27,17 a A & 24,12 a AB & 13,54 b B & 10,71 b B \\
S10 & 25,33 a A & 26,38 a A & 23,79 a AB & 13,58 b B & 3,50 c B \\
S11 & 24,33 a A & 25,71 a A & 19,21 b B & 3,50 c B & 1,92 c C \\
\hline
\end{tabular}

Médias seguidas de mesma letra minúscula (na linha) e maiúscula (na coluna), não diferem entre si pelo Teste de Tukey a 5\%. S1Solo A em condição natural, S2-Solo B em condição natural, S3-Solo A com adubação mineral, S4-Solo B com adubação mineral, S5-Mistura de $80 \%$ de solo A e $20 \%$ de R.S.O.U., S6-Mistura de $80 \%$ de solo B e $20 \%$ de R.S.O.U., S7-Mistura de $60 \%$ de solo A e $40 \%$ de R.S.O.U., S8-Mistura de $60 \%$ de solo B e $40 \%$ de R.S.O.U., S9-Mistura de $20 \%$ de solo A e $80 \%$ de R.S.O.U. S10-Mistura de $20 \%$ de solo B e $80 \%$ de R.S.O.U., S11-R.S.O.U. puro.

Para as variáveis, altura média de plantas e número médio de folhas por planta (Figura 1), avaliadas aos 79 dias após a semeadura, a adição crescente de R.S.O.U. nos substratos (de 20 a 100\%) apresentou um efeito negativo proporcional às quantidades utilizadas, entretanto, o crescimento foi homogêneo em todos os substratos, nas diferentes idades.

Cravo (1995) verificou aumento nos teores trocáveis de potássio e de cálcio, em função de doses de composto de até $120 \mathrm{t} \mathrm{ha}^{-1}$, tanto em um solo arenoso quanto em outro argiloso. Porém, o magnésio teve seu teor aumentado somente no solo arenoso.

Todavia, a contribuição do composto de lixo na Capacidade de Troca Catiônica - CTC de solos sob clima tropical é baixa, indicando que somente aplicações consecutivas de doses elevadas do composto aumentarão significativamente a CTC desses solos (LIMA et al., 1999; OLIVEIRA, 2000).

Aplicações sucessivas e em elevadas doses do composto de lixo, todavia, sem o devido monitoramento, podem causar efeitos negativos ao solo e às plantas. A salinização, avaliada pela condutividade elétrica (GARCIA et al., 1992, ABREU JR. et al., 2000; OLIVEIRA et al., 2002), o acúmulo de metais (CRAVO et al., 1998; SILVA et al., 2006), a lixiviação de nitratos (OLIVEIRA, 2000; MONTOVANI, 2005) e, a dispersão dos colóides e redução da condutividade hidráulica do solo, decorrentes da substituição do cálcio e magnésio da interface solução do solosuperfície coloidal pelo sódio e potássio, presentes em altas concentrações no composto de lixo (MELO et al., 1997), são os principais aspectos ambientais a serem monitorados para o sucesso desta prática. 


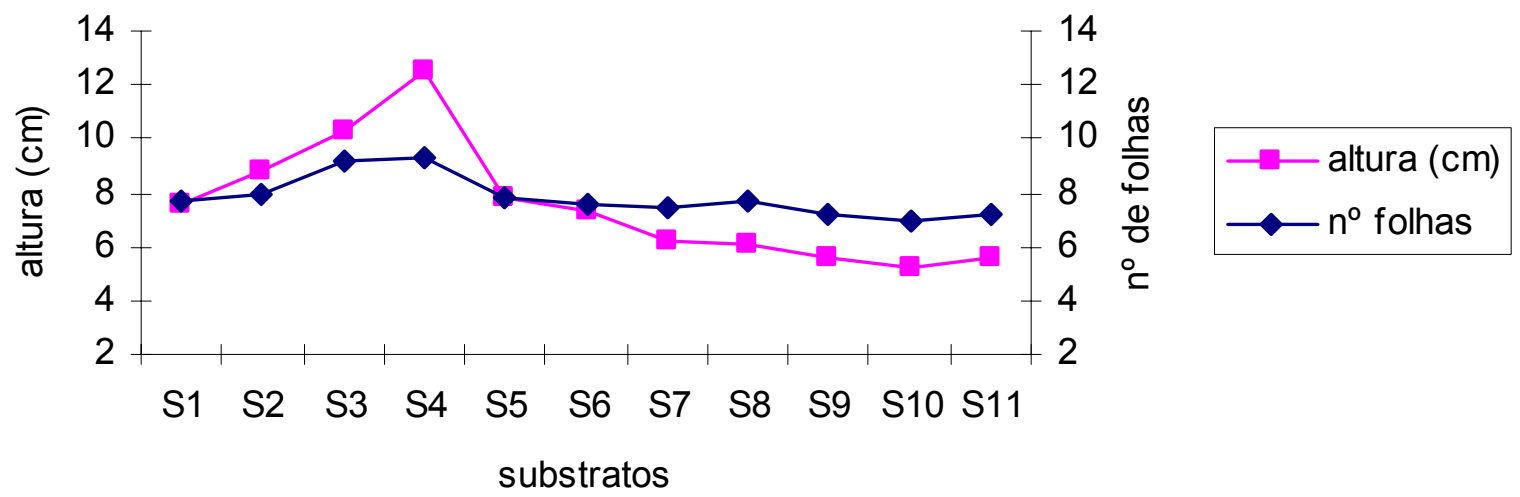

S1-Solo A em condição natural, S2-Solo B em condição natural, S3-Solo A com adubação mineral, S4-Solo B com adubação mineral, S5-Mistura de $80 \%$ de solo A e $20 \%$ de R.S.O.U., S6-Mistura de $80 \%$ de solo B e $20 \%$ de R.S.O.U., S7-Mistura de $60 \%$ de solo A e $40 \%$ de R.S.O.U., S8-Mistura de $60 \%$ de solo B e $40 \%$ de R.S.O.U., S9-Mistura de $20 \%$ de solo A e $80 \%$ de R.S.O.U. S10Mistura de $20 \%$ de solo B e $80 \%$ de R.S.O.U., S11-R.S.O.U. puro.

FIGURA 1. Altura média de plantas $(\mathrm{cm})$ e número médio de folhas por planta, avaliadas aos 79 dias após a semeadura.

Analisando a interação entre os substratos e os tipos de irrigação (Tabela 5), verifica-se que na irrigação conduzida pelo método do tanque classe A, o S5 foi o que apresentou maior número médio de tubetes com plantas vivas, não apresentando diferença estatística com S2 e S4. No método de condução da irrigação pela massa, o maior número de tubetes com plantas vivas foi identificado no $\mathrm{S} 2$, sendo que houve diferença estatística somente nos tratamentos S9, S10 e S11. Exceto para o S11, o método de condução da irrigação pela massa, foi superior ao método do tanque classe A, finalizando com maior número de tubetes com plantas vivas.

TABELA 5 - Valores médios do número de tubetes com plantas vivas, em função do tipo de irrigação (TCA e PS).

\begin{tabular}{|c|c|c|}
\hline \multirow[t]{2}{*}{ substrato } & \multicolumn{2}{|c|}{ Métodos } \\
\hline & TCA & PS \\
\hline S1 & $17,33 \quad b \quad C D$ & $25,93 \mathrm{aAB}$ \\
\hline S2 & $18,28 \mathrm{bABC}$ & $28,48 \mathrm{aA}$ \\
\hline S3 & $14,00 \quad b \quad D$ & $26,18 \mathrm{aABC}$ \\
\hline S4 & 21,42 bAB & $28,20 \mathrm{aA}$ \\
\hline S5 & 21,68 bA & $27,12 \mathrm{aA}$ \\
\hline S6 & $15,80 \quad \mathrm{~b} \quad \mathrm{CD}$ & $26,48 \mathrm{aAB}$ \\
\hline S7 & $16,25 \quad b \quad C D$ & $27,90 \mathrm{aA}$ \\
\hline S8 & $16,15 \quad b \quad C D$ & $27,47 \mathrm{aA}$ \\
\hline S9 & 17,78 b $\mathrm{BC}$ & 22,75 a $\quad C$ \\
\hline S10 & $15,87 \quad b \quad C D$ & 23,32 a $B C$ \\
\hline S11 & $15,12 \mathrm{a} \quad \mathrm{CD}$ & $14,75 \mathrm{a}$ \\
\hline
\end{tabular}

Médias seguidas de mesma letra minúscula (na linha) e maiúscula (na coluna), não diferem entre si pelo Teste de Tukey a 5\%. S1Solo A em condição natural, S2-Solo B em condição natural, S3-Solo A com adubação mineral, S4-Solo B com adubação mineral, S5-Mistura de $80 \%$ de solo A e $20 \%$ de R.S.O.U., S6-Mistura de $80 \%$ de solo B e $20 \%$ de R.S.O.U., S7-Mistura de $60 \%$ de solo A e $40 \%$ de R.S.O.U., S8-Mistura de $60 \%$ de solo B e $40 \%$ de R.S.O.U., S9-Mistura de $20 \%$ de solo A e $80 \%$ de R.S.O.U. S10-Mistura de $20 \%$ de solo B e $80 \%$ de R.S.O.U., S11-R.S.O.U. puro. 
Para as variáveis altura média de plantas e número médio de folhas por planta Figura 2, avaliadas aos 15, 29, 41 e 79 dias após a semeadura, nos dois métodos de condução da irrigação, os tratamentos sem a presença de R.S.O.U. (S1, S2, S3 e S4) apresentaram valores superiores aos demais.
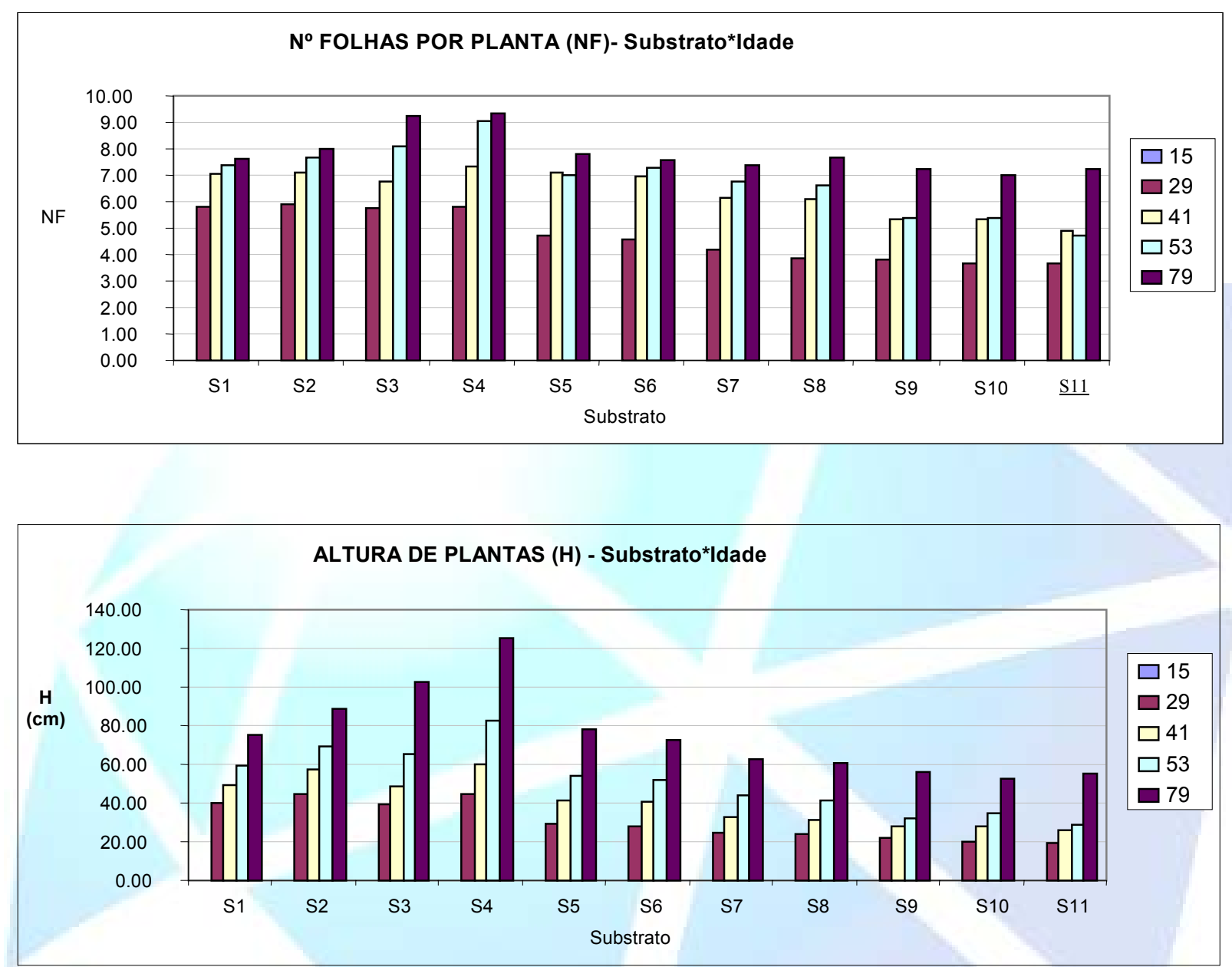

S1-Solo A em condição natural, S2-Solo B em condição natural, S3-Solo A com adubação mineral, S4-Solo B com adubação mineral, S5-Mistura de $80 \%$ de solo A e $20 \%$ de R.S.O.U., S6-Mistura de $80 \%$ de solo B e $20 \%$ de R.S.O.U., S7-Mistura de $60 \%$ de solo A e $40 \%$ de R.S.O.U., S8-Mistura de $60 \%$ de solo B e $40 \%$ de R.S.O.U., S9-Mistura de $20 \%$ de solo A e $80 \%$ de R.S.O.U. S10Mistura de $20 \%$ de solo B e $80 \%$ de R.S.O.U., S11-R.S.O.U. puro.

FIGURA 2. Altura média de plantas $(\mathrm{cm})$ e número médio de folhas por planta, avaliadas aos 15 , 29, 41 e 79 dias após a semeadura, em função do tipo de irrigação.

À medida que se aumentou à porcentagem de R.S.O.U., foi menor o desenvolvimento em altura das plantas e o número médio de folhas por planta. $\mathrm{O}$ efeito prejudicial ao desenvolvimento das plantas pode ser pelo fato do R.S.O.U. ter sido utilizado sem a compostagem, para tentar diminuir o período entre a coleta do lixo e a sua utilização, concordando com Kiehl (1985), que o composto orgânico utilizado como fertilizante resulta de um processo de decomposição bioquímica de materiais orgânicos, transformado-os em um produto mais estável. 
Ao comparar o número de tubetes com plantas vivas nos diferentes substratos e níveis de irrigação Tabela 6 , verifica-se que no nível de $50 \%$ da evapotranspiração, o substrato S11 apresentou o menor número de tubetes com plantas vivas, embora não diferindo estatisticamente dos substratos S3, S6, S9 e S10.

TABELA 6 - Número médio de tubetes com plantas vivas nos substratos, em cada nível de irrigação.

\begin{tabular}{|c|c|c|c|c|}
\hline \multirow[t]{2}{*}{ Substrato } & \multicolumn{4}{|c|}{ Nível de irrigação } \\
\hline & $50 \%$ & $75 \%$ & $100 \%$ & $130 \%$ \\
\hline S1 & 22,63 a $\mathrm{A}$ & $23,00 \mathrm{a} A B$ & 21,70 a $\mathrm{ABC}$ & 19,17 a $\mathrm{AB}$ \\
\hline S2 & 22,53 a $\mathrm{A}$ & 23,18 a $\mathrm{AB}$ & 24,20 a $A B$ & 23,60 a $\mathrm{A}$ \\
\hline S3 & 18,07 a $A B$ & 21,90 a $A B$ & 20,77 a $\mathrm{ABC}$ & 19,63 a $A B$ \\
\hline S4 & 20,93 bA & 26,83 a $\mathrm{A}$ & 26,23 a $\mathrm{A}$ & 25,23 a $\mathrm{A}$ \\
\hline S5 & 22,17 bA & 26,03 a $A B$ & $24,47 \mathrm{abAB}$ & $24,93 \mathrm{abA}$ \\
\hline S6 & 20,67 a $A B$ & 20,33 a $B$ & 20,43 a $\mathrm{AB}$ & 23,13 a $\mathrm{A}$ \\
\hline S7 & 21,30 a $\mathrm{A}$ & 21,47 a $A B$ & 22,43 a $A B$ & 23,10 a $\mathrm{A}$ \\
\hline S8 & 20,87 a $\mathrm{A}$ & 22,05 a $A B$ & 23,13 a $A B$ & 20,73 a $A B$ \\
\hline S9 & 18,73 a $\mathrm{AB}$ & $23,00 \mathrm{a} A B$ & 20,37 a $A B$ & 18,97 a $\mathrm{AB}$ \\
\hline $\mathrm{S} 10$ & 18,97 a $\mathrm{AB}$ & $20,30 \mathrm{a} \quad \mathrm{B}$ & $19,67 \mathrm{a} \quad \mathrm{BC}$ & 19,43 a $A B$ \\
\hline S11 & $14,10 \mathrm{a} \quad \mathrm{B}$ & 14,07 a $\mathrm{AC}$ & $16,53 \mathrm{a}$ & $15,03 \mathrm{a} \quad \mathrm{B}$ \\
\hline
\end{tabular}

Médias seguidas de mesma letra minúscula (na linha) e maiúscula (na coluna), não diferem entre si pelo Teste de Tukey a 5\%. S1Solo A em condição natural, S2-Solo B em condição natural, S3-Solo A com adubação mineral, S4-Solo B com adubação mineral, S5-Mistura de $80 \%$ de solo A e $20 \%$ de R.S.O.U., S6-Mistura de $80 \%$ de solo B e $20 \%$ de R.S.O.U., S7-Mistura de $60 \%$ de solo A e $40 \%$ de R.S.O.U., S8-Mistura de $60 \%$ de solo B e $40 \%$ de R.S.O.U., S9-Mistura de $20 \%$ de solo A e $80 \%$ de R.S.O.U. S10-Mistura de $20 \%$ de solo B e $80 \%$ de R.S.O.U., S11-R.S.O.U. puro.

No nível de irrigação $75 \%$ da evapotranspiração, o melhor resultado observado foi no S4, embora diferenciando estatisticamente apenas dos S6, S10 e S11. Para o nível de irrigação de $100 \%$ da evapotranspiração, o substrato que melhor se comportou em relação ao número de tubetes com plantas vivas foi $\mathrm{S} 4$, embora tenha apenas diferido estatisticamente, do S10. O substrato S11 foi o que apresentou menor número de tubetes com plantas vivas no nível de irrigação de $130 \%$ da evapotranspiração, embora não difere estatisticamente dos substratos S1, S3, S9 e S10. Os substratos de S1 a S10 não apresentaram diferença estatística.

Os resultados mostram que o aumento na quantidade de água aplicada proporcionou maior número de tubetes com plantas vivas, havendo uma relação direta entre os níveis de água e o número de tubetes com plantas vivas, apesar de, estatisticamente, ter sido significativo apenas no substrato S5. O efeito físico causado pela matéria orgânica no solo é importante para o desenvolvimento dos vegetais. Segundo Henin et al. (1976), seu efeito na melhoria da estrutura do solo constitui um fator positivo para o desenvolvimento das raízes. Esta melhoria está relacionada, também, com o regime de água, pois, melhorando a capacidade de infiltração, se acelera o processo dinâmico da água no solo.

Conforme observado na Figura 3, o número de tubetes com plantas vivas em relação aos métodos de controle da irrigação, o da pesagem apresentou melhores resultados do que pelo tanque classe $\mathrm{A}$, em qualquer uma das épocas de avaliação. 
Pôde-se verificar ainda que se obteve os melhores resultados aos de 15 e 29 dias após a semeadura tanto para o método de condução da irrigação pelo tanque classe A quanto para o método de condução de irrigação pela pesagem dos substratos.

O número de folhas por planta foi crescente com o aumento da idade das mudas, nos dois métodos de condução da irrigação. Entretanto, na análise aos 79 dias após a semeadura, o crescimento foi maior pelo método da irrigação do tanque classe A Figura 4.

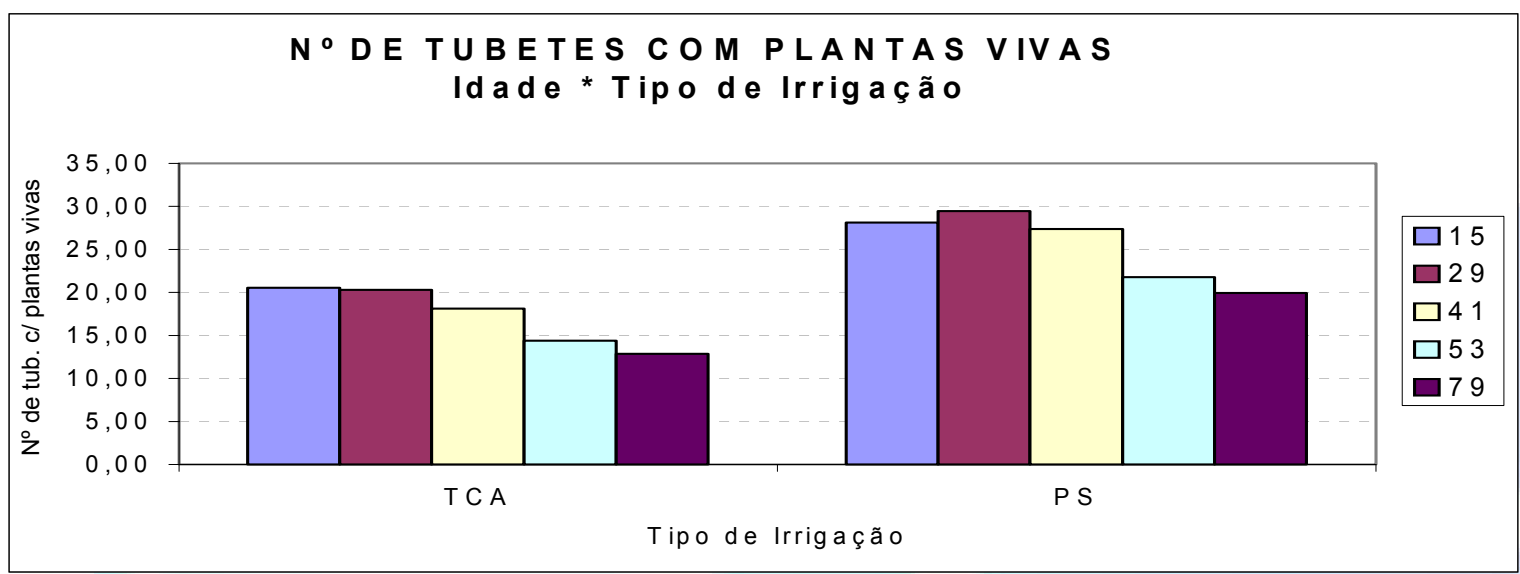

FIGURA 3. Número médio de tubetes com plantas vivas em função do tipo de irrigação (TCA: Tanque Classe A e PS: massa) e da época de avaliação (dias após a semeadura).

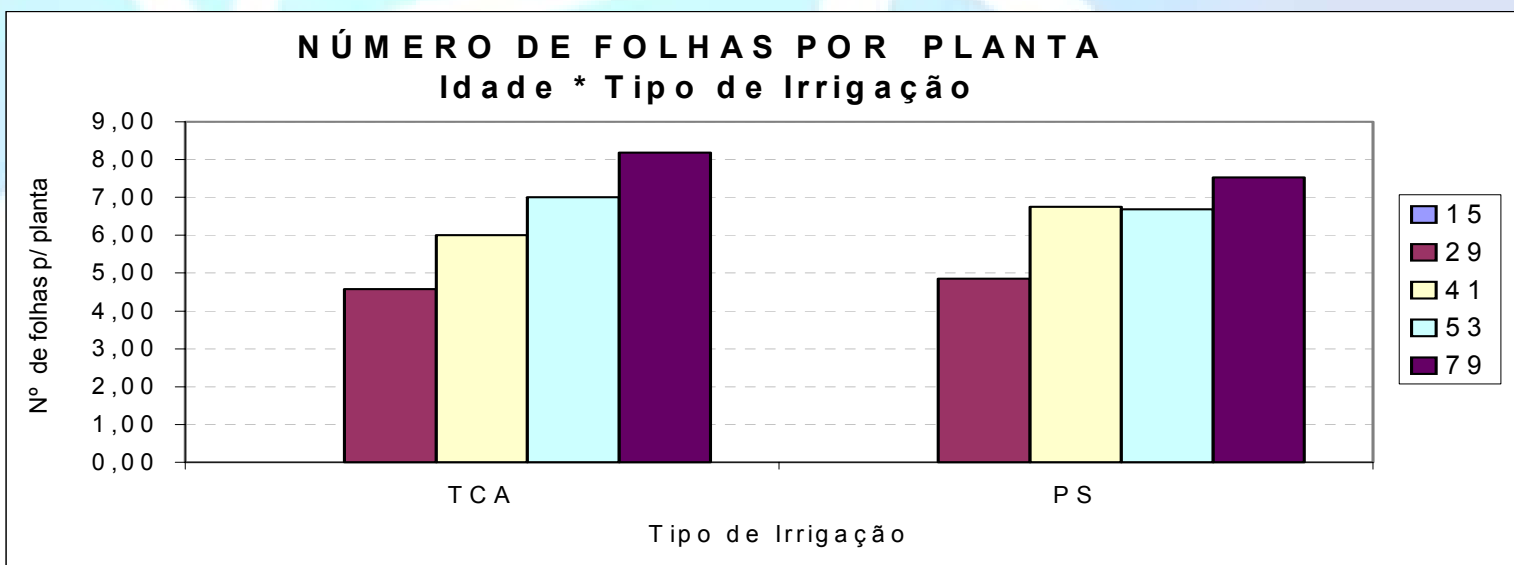

FIGURA 4. Número médio de folhas por plantas, em função do tipo de irrigação (TCA: TanqueClasse A e PS: massa) e da época de avaliação (dias após a semeadura).

Finalmente, em relação à altura média de plantas, não se constatou diferenças estatísticas significativas entre os níveis de irrigação, como também para o método de condução da irrigação Tabela 7. 
TABELA 7 - Altura média das plantas (mm), analisadas em função da irrigação.

\begin{tabular}{cccccc}
\hline Variável & TI & \multicolumn{4}{c}{ Níveis de irrigação (\%ET) } \\
\cline { 2 - 5 } & & 50 & 75 & 100 & 130 \\
\hline Altura das & TCA & $46,17 \mathrm{aA}$ & $48,29 \mathrm{aA}$ & $46,54 \mathrm{bA}$ & $48,57 \mathrm{aA}$ \\
plantas & PS & $49,03 \mathrm{aA}$ & $52,41 \mathrm{aA}$ & $52,69 \mathrm{aA}$ & $50,97 \mathrm{aA}$ \\
\hline \multicolumn{2}{l}{$\begin{array}{l}\text { Médias seguidas da mesma letra, na coluna } \\
\text { Tipo de método de cálculo da irrigação. TCA- Tanque Classe A. PS- Determinação da massa. }\end{array}$}
\end{tabular}

\section{CONCLUSÃO}

A utilização de Resíduo Sólido Orgânico Urbano (R.S.O.U.) como mistura em substratos, sem passar pelo processo de compostagem, prejudica o desenvolvimento das mudas de eucalipto.

Para níveis de irrigação, as misturas de R.S.O.U. não diferiram estatisticamente para a maior parte dos tratamentos, contudo, para os demais valores, constatou-se que, misturas a partir de $20 \%$ de R.S.O.U. apresentam tendência a diminuir o número de plantas vivas.

Existe uma relação indireta entre adições de R.S.O.U., crescimento e número de folhas das plantas.

O método das pesagens para cálculo da irrigação é mais eficiente nas condições que se desenvolveu este trabalho.

\section{REFERÊNCIAS}

ABREU JR., C.H.; MURAOKA, T.; LAVORANTE, A.F.; ALVAREZ V., F.C. Condutividade elétrica, reação do solo e acidez potencial em solos adubados com composto lixo. Revista Brasileira de Ciência do Solo, Viçosa, v.24, n.4, p.635-647, out./dez. 2000.

ANDRIOLI, I.; SACCHI, E.; NISHIDA, L. T., CENTURION, J. F. Efeito de modalidades de preparo e da aplicação de um composto orgânico nas propriedades físicas de um latossolo vermelho escuro textura média nas culturas de soja e milho. In: CONGRESSO BRASILEIRO DE CIÊNCIA DO SOLO, 23.1991. Porto Alegre. Anais... Porto Alegre: Sociedade Brasileira de Ciência do Solo, 1991, p.143.

BRAUN, R. Effect of compost on plant and soil. In: INTERNATIONAL

CONGRESS OF PUBLIC CLEANSING, 8., 1964, Viena. Anais... Viena, 1964. CARVALHO, C. M. Produção de mudas de espécies florestais de rápido crescimento. In: NOVAES, A. B. et al. Reflorestamento no Brasil. Vitória da Conquista-BA, UESB, 1992. p. 93-103. 
CRAVO, M.S. Composto de lixo urbano como fonte de nutrientes e metais pesados para alface. Piracicaba, 1995. 148p. Tese (Doutorado em Agronomia Solos e Nutrição de Plantas) Escola Superior de Agricultura "Luiz de Queiroz", Universidade de São Paulo.

CRAVO, M.S.; MURAOKA, T.; GINE-ROSIAS, M.F.G. Caracterização química de compostos de lixo urbano de algumas usinas brasileiras. Revista Brasileira de Ciência do Solo, Viçosa, v.22, n.3, p.547-553, jul./set.1998.

DAY, P.R. Particle fracionation and particle - size analysis. In: BLACK, C.A. Methods of soil analysis. Madison: Americam Society of Agronomy, 1965. part 1, cap. 43, p.545-567. (ASA, 9).

EMBRAPA - EMPRESA BRASILEIRA DE PESQUISA AGROPECUÁRIA. Serviço Nacional de Levantamento e Conservação Do Solo. Manual de métodos de solo. Rio de Janeiro: Ministério da Agricultura, 1979.

FERNANDEZ, J. E.; MORENO, F.; HERNANDÉZ, J. M.: MURILLO, J. M. Influência del aporte continuado de resíduos sólidos urbanos sobre propriedades físicas del suelo, In: CONGRESSO NACIONAL DE QUÍMICA, 7., 1987, Sevilha.Anais... Servilha, 1987.

FONSECA, E. P. Padrão de qualidade de mudas de Trema micrantha (L.) Blume., Cedrela fissilis Vell. e Aspidosperma polyneuron Müll. Arg. produzidas sob diferentes períodos de sombreamento. Jaboticabal: Universidade Estadual Paulista, 2000. 113 p. Tese (Doutorado em Agronomia - Produção Vegetal) Universidade Estadual Paulista.

GALBIATTI, J. A. Efeito do uso contínuo de efluente de biodigestos sobre algumas características físicas do solo e o comportamento do milho (Zea Mays L.). Jaboticabal. 1992. 212f. Tese (Livre Docente) - Faculdade de Ciências Agrárias e Veterinárias, Universidade Estadual Paulista, Jaboticabal.

GARCIA, C.; HERNÁNDEZ, T.; COSTA, F.; PASCUAL, J.A. Phytotoxicity due to the agricultural use of urban wastes. Germination experiments. Journal Science Food Agricultural, Cambridge, v.59, n.3, p. 313 - 319, 1992.

GOMES, J. M.COUTO, L.; BORGES, R. C. G.; FONSECA, E. P. . Efeito de diferentes substratos na produção de mudas de Eucalyptus grandis W. Hill ex Maiden, em "Win-Strip". Revista Árvore, Viçosa, v. 15, n. 1, p. 35-42, jan.1991. 
HENIN, S.; GRAS, R.; MONNIER, G. Os solos agrícolas. Rio de Janeiro: Forense, Universitária, 1976. $327 \mathrm{p}$.

IBGE - INSTITUTO BRASILEIRO DE GEOGRAFIA E ESTATÍSTICA. Departamento de Cartografia. Carta do Brasil: Jaboticabal, Taiúva e Pitangueiras. São Paulo; 1971. Escala 1:50.000.

JAHNEL, M. C., MELLONI, R., CARDOSO, E. J. B. N. Maturidade de composto de lixo urbano. Scientia Agricola Piracicaba, v.56, n.2, p.301-304, 1999.

KIEHL, E. J. Fertilizantes orgânicos. São Paulo: Agronômica Ceres, 1985. 492p. Official Methods of Analysis of Association of Official Chemists, Washington, 1970

LIMA, J.S.; LICHTIG, J.; Oliveira E.; MENK, J.R.F. Hortaliças cultivadas com composto orgânico de lixo urbano não apresentam contaminação com metais pesados. Revista Ceres, Viçosa, v.46, n.268, p.571-585, nov./dez.1999.

LOPES, J. L. W. Efeitos na irrigação na sobrevivência, transpiração e no teor relativo de água na folha em mudas de Eucalyptus grandis em diferentes substratos. Scientia Forestalis, Piracicaba, n.68, p.97-106, ago. 2005.

MELO,W. J.; MARQUES, M.O.; SILVA, F.C.; BOARETTO, A.E. Uso de resíduos sólidos urbanos na agricultura e impactos ambientais (Compact disc). In:

CONGRESSO BRASILEIRO DE CIÊNCIA DO SOLO, 26., Rio de Janeiro, 1997. Anais... Rio de Janeiro: Embrapa; SBCS, 1997.

MONTOVANI, J. R.; FERREIRA, M. E.; CRUZ, M. C. P. Alterações nos atributos de fertilidade do solo adubado com composto de lixo urbano. Revista Brasileira de Ciência do Solo, Viçosa, v.29, n.5, p. 817-824, set./out. 2005

OLIVEIRA, F.C. Disposição de lodo de esgoto e composto de lixo urbano num latossolo vermelho-amarelo cultivado com cana-de-açúcar. Piracicaba, 2000. 247p. Tese (Doutorado em Agronomia - Solos e Nutrição de Plantas) - Escola Superior de Agricultura "Luiz de Queiroz", Universidade de São Paulo.

OLIVEIRA, F. C.; MATTIAZZO, M. E.; MARCIANO, C. R.; ABREU JUNIOR, C.H. Alterações em atributos químicos de um latossolo pela aplicação de composto de lixo urbano. Pesquisa Agropecuária Brasileira, Brasília, v. 37, n.12, p. 529-538, dez. 2002.

RAIJ, B. van; ZULLO, M.A.T. Métodos de análise do solo para fins de fertilidade. Campinas: Instituto Agronômico, 1977. 16p. (IAC. Circular, 63). 
RAIJ, B. van; QUAGGIO, J.A.; CANTARELLA, H.; FERREIRA, M.E.; LOPES, A.S.; BATAGLIA, O.C. Análise química do solo para fins de fertilidade. Campinas: Fundação Cargil, 1987. 170p.

RUIZ, H. A.; TEIXEIRA, E. A. Retenção de água em materiais de solos tratados com dois compostos orgânicos. In: CONGRESSO BRASILEIRO DE CIÊNCIA DO SOLO, 23., 1991, Porto Alegre. Anais... Porto Alegre: Sociedade Brasileira de Ciência do Solo, 1991.

SILVA, F. C.; SILVA, C. A.; BERGAMASCO, A. F. Disponibilidade de micronutrientes em cinco solos em função do tempo de incubação de um composto de lixo. Engenharia Agrícola, Jaboticabal, v.26, n.1, p. 224-234, 2006.

VERAS, L. R. V. A vermicompostagem do lodo de lagoas de tratamento de efluentes industriais consorciado com composto de lixo urbano. Engenharia Sanitária Ambiental. v. 9, n. 3, p. 218-224, jul/ set. 2004.

XIN, T. H.; TRAINA, S. J.; LOGAN, T.J. Chemical properties of municipal solid waste compost. Journal of Environmental Quality, v.21, p.318-329, 1992. 